\title{
Correlation of Dermatoglyphic Interpretation with Oral Diseases- Revisited
}

\author{
Amit Manik ${ }^{1}$,Mitesh Parekh ${ }^{2}$, Rajat Varshney ${ }^{3}$, Tarun Vyas ${ }^{4}$ \\ ${ }^{1}$ Post Graduate student, ${ }^{2}$ Professor,. ${ }^{3}$ Reader, Department of Oral Pathology and Microbiology, Darshan \\ Dental College and Hospital, Udaipur, ${ }^{4}$ Post Graduate student Department of Oral Medicine and \\ Rdiology, Darshan Dental College and Hospital, Udaipur
}

\begin{abstract}
From the time of early civilization, the characteristic pattern of the hands have been an area of interest to predict the future. Over the years of scientific research, these features of hand has come to be considered as a useful tool in the diagnosis of psychological, genetic and other medical conditions. Epidermal ridge patterns form early in fetal development and they remain unchanged throughout life and hence they could be used to indicate gene or chromosomal abnormalities. Thus, the dermatoglyphic patterns may be utilized effectively to study the genetic basis of various diseases in developing counteries, as it is a noninvasive, inexpensive and effective tool for screening and foretell the probability of occurrence of various diseases. The present review aims to discuss various pattern of fingerprints and briefly discusses importance of fingerprints in prediction of oral diseases.
\end{abstract}

Keywords: Dermatoglyphics; Epidermal ridge patterns; Fingerprints

Corresponding author: Amit Manak, PG Student,Department of Oral Pathology and Microbiology, Darshan Dental College and Hospital, Udaipur. Email: amitmanik23@gmail.com

This article may be cited as: Manik A, Parekh M, Varshney R and Vyas T.Correlation of Dermatoglyphic interpretation with oral diseases- revisited. Int J Com Health and Med Res 2016;2(2):56-59

Article Received: 18-02-16

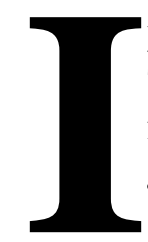

NTRODUCTION

The word 'dermatoglyphics' is derived from two Greek words i.e. derma, skin and glyphe, carve. It refers to the epidermal skin ridge formations which appear on the fingers, palms of the hands and soles of the feet. This term was coined by Harold Cummins in 1926. ${ }^{1}$ The science of dermatoglyphics involves the study of epidermal ridges present on the surface of palms, fingers, soles and toes. These epidermal ridges form well-defined patterns that characterise individuals and they have been found useful in the clinical diagnoses of hereditary diseases. Epidermal ridge patterns form early in fetal development and they remain unchanged throughout life and hence they could be used to indicate gene or chromosomal abnormalities. ${ }^{2}$ Abnormalities in these areas are influenced by a combination of hereditary and environmental

\section{Accepted On: 05-05-2016}

factors, but only when the combined factors exceed a certain level, can these abnormalities be expected to appear. ${ }^{3}$ Fuller IC $^{4}$ conducted a study to evaluate dermatoglyphics of patients suffering from diabetes, schizophrenia, duodenal ulcer, asthma, and various cancers and reported significant differences in the digital ridge counts, maximum atd angles, and distal palmar loop ridge counts have been found. A discriminant analysis of the digital ridge counts was performed and the function was used to attempt differential diagnosis between these conditions on dermatoglyphic evidence alone. However, diagnostic trial failed, and the author revealed that the possible reasons for its failure are the relevance of dermatoglyphics is not to diagnosis, but to prognosis; not to the definition of existing disease, but to the identification of people with the genetic predisposition to develop certain diseases. Thus, 
here lies the importance of the investigation of dermatoglyphics in diseases; i.e. not the academic identification of associations, but their practical application in screening inexpensively, populations at risk so that a watch may be kept for the early onset symptoms.

\section{Types of fingerprints}

In 1892, Sir Francis Galton published his highly influential book, 'Finger Prints' in which he described his classification system based on the number of triradii. Galton's fingerprint system included the three major patterns of fingerprint types:

I) Arch: Arches have no triradii. ${ }^{5}$ Tri-radius is formed by the confluence of three ridge systems that form angles of approximately 120 o with one another.

Arch pattern is further classified into plain and tented arch.

II) Loop: Loops have one triradius, and is further classified into Ulnar and Radial loop.

III) Whorl: whorls have two triradii. The 'whorl' is characterised by a pattern of concentric circles, or a spiral shape - some of the ridges make a turn through at least. This pattern is further classified into plain whorl; Central pocket loop; Double loop and Accidental whorl. ${ }^{5}$

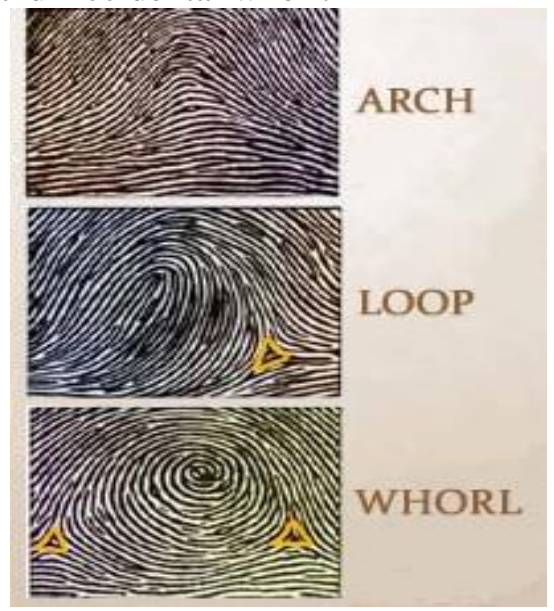

Figure 1: Classification of finger pattern ${ }^{5}$

\section{Dermatoglyphics and oral diseases}

Sharma $\mathrm{R}$ et $\mathrm{al}^{6}$ determine if there is any significant correlation between salivary bacteria interactions, dermatoglyphics, and dental caries and found that subject group had a decreased frequency of loops, whereas control group had an increased frequency of loops on all palmar digits. Similarly, Abhilash PR et al $^{7}$ investigated and analyzed the significance of dermatoglyphics in predicting the susceptibility of individuals to develop dental caries and reported that the dental caries susceptibility of an individual increased with incidence of whorl pattern and it decreased with incidence of loop pattern.Gupta $\mathrm{A}$ et $\mathrm{al}^{8}$ conducted a study to analyze the palmar dermatoglyphics in squamous cell carcinoma (SCC) and oral submucous fibrosis (OSF) and revealed that in SCC, there was an increase in frequency of arch and ulnar loop patterns on fingertips, decrease in frequency of simple whorl patterns on fingertips, decrease in frequency of palmar accessory triradii on right and left hands. Significant findings in OSF included an increase in frequency of arch and ulnar loop pattern, decrease in frequency of simple whorl patterns on fingertips, decrease in atd angle on right hand, decrease in frequency of palmar accessory triradii on right hand. The results revealed that the field of dermatoglyphics holds promising results for determining the genetic susceptibility of individuals to develop SCC and OSF. Ganvir SM et $\mathrm{al}^{9}$ evaluated the genetic predisposition and frequency of specific finger and palm-print patterns in OSCC and OSMF patients by dermatoglyphic analysis and found that whorl type of fingerprint pattern was predominant in significantly higher number of individuals of OSCC and OSMF group than in control groups, whereas individuals of both the control groups showed loop as a predominant fingerprint pattern. This indicates that the predominance of whorl type of fingerprint pattern would serve as a candidate screening marker for susceptibility to oral squamous cell carcinoma and oral submucous fibrosis in general population with or without tobacco chewing habit.Kumar $\mathrm{S}$ et $\mathrm{al}^{10}$ determined the fingerprint patterns in gutkha chewers with oral submucous fibrosis (OSMF) and in healthy controls without gutkha chewing habit and OSMF and found a marked decrease of tented arches, ulnar and radial loops, and an increase of simple whorls in OSMF subjects in comparison with normal individuals. Atasu $M$ et $\mathrm{al}^{11}$ evaluated dermatoglyphic findings in patients with periodontal diseases and reported that dermatoglyphics could be used together with the other diagnostic methods such as clinical and 
radiologic investigations and in the identifying of the patients from distinct groups of periodontal diseases. Jahanbin A et al $^{12}$ conducted a study to test the hypothesis that unaffected parents with nonsyndromic bilateral cleft lip and palate children possess greater levels of dermatoglyphic asymmetry than the normal population and to test for the difference in the distribution of pattern types and the findings suggested that an increase in the asymmetry of atd angles and pattern types in parents of sporadically affected children may reflect more the genetic base of this congenital malformation. Maheshwari $\mathrm{N}$ et $\mathrm{al}^{13}$ conducted a study to observe and compare the differences in the dermatoglyphic patterns between cleft lip/palate $(\mathrm{CL} / \mathrm{P})$ and normal healthy children and concluded that any deviation in dermatoglyphics features indicates a genetic etiology. Madura $\mathrm{MG}^{14}$ carried out a review of literature and concluded that analysis of dermatoglyphic pattern can prove to be a significantly useful tool for preliminary investigations in those conditions with a suspected genetic base.

\section{CONCLUSION}

The individuality of a person's finger prints led to the analysis of one's potential, personality and preferences by analyzing dermatoglyphics. The individuality is because of the reason that Dermatoglyphics is the reflection of DNA and consequently does not change. ${ }^{3}$ Thus, the dermatoglyphic patterns may be utilized effectively to study the genetic basis of various diseases. in developing counteries, as it is a noninvasive, inexpensive and effective tool for screening and foretell the probability of occurrence of various diseases.

\section{REFERENCES}

1. Prabhu N, Issrani R, Mathur $S$, Mishra G, Sinha S (2014) Dermatoglyphics in Health and Oral Diseases-A Review. JSM Dent 2(4): 1044.

2. Igbigbi PS, BC Msamati BC, Ng'ambi TM. Plantar and digital dermatoglyphic patterns in Malawian patients with diabetes, hypertension and diabetes with hypertension. Int J Diabetes \& Metabolism (2001) 9: 24-31

3. Lakshmi Prabha J, Thenmozhi.R. A Short Review on Dermatoglyphics. J. Pharm. Sci. \& Res. Vol. 6(4), 2014, 200-202
4. Fuller IC. Dermatoglyphics: A Diagnostic Aid? Journal of Medical Genetics 1973;10:165-9.

5. Martijin van Mensvoort. The Mystery of a 'Mount of Moon Whorl' unveiled! OCTOBER 11, 2009. Available at: http://www.handresearch.com/news/whorlmount-of-moon-hypothenar-whorlsautism.htm

6. Sharma A, Somani R. Dermatoglyphic interpretation of dental caries and its correlation to salivary bacteria interactions: An in vivo study 2009;27(1):17-21.

7. Abhilash PR, Divyashree R, Patil SG, Gupta M, Chandrasekar T, Karthikeyan R. Dermatoglyphics in Patients with Dental Caries: A Study on 1250 Individuals. J Contemp Dent Pract 2012;13(3):266-274.

8. Gupta A, Karjodkar FR. Role of dermatoglyphics as an indicator of precancerous and cancerous lesions of the oral cavity. Contemporary Clinical Dentistry 2013;4(4):448-53.

9. Ganvir SM, Gajbhiye NY. Detection of genetic predisposition in oral squamous cell carcinoma (OSCC) and oral submucous fibrosis patients by qualitative analysis of finger and palm-print patterns: A dermatoglyphic study. Clin Cancer Investig 2014;3:377-82.

10. Kumar S, Kandakurti S, Saxena VS, Sachdev AS, Gupta J. A dermatoglyphic study in oral submucous fibrosis patients. J Indian Acad Oral Med Radiol 2014;26:269-73.

11. Atasu M, Kuru B, . Firatli E, Meri H. Dermatoglyphic findings in periodontal diseases. International Journal of Anthropology 2005;20(1):63-75.

12. Jahanbin A, Mahdavishahri N, Naseri MM, Sardari Y, Rezaian S. Dermatoglyphic Analysis in Parents With Nonfamilial Bilateral Cleft Lip and Palate Children. Cleft Palate-Craniofacial Journal 2010;47(1):9-14.

13. Maheshwari N, Bansal K, Rao DJ, Chopra R. Comparison of dermatoglyphic traits and dental anomalies associated with cleft lip or cleft lip and palate patients with 
normal healthy children. J Indian Soc Pedod Prev Dent 2013;31:260-4.

14. Madhura MG. Dermatoglyphics in oral diseases- a review. International journal of current research and review 2015;7(7):724.

Source of support: Nil

Conflict of interest: None declared

This work is licensed under CC BY: Creative Commons Attribution 4.0 License. 